\title{
Beiträge zur Kenntnis der Blattasymmetrie und Exotrophie.
}

Von K. Boshart.

(Mit 14 Abbildungen im Text.)

Den ersten Hinweis auf die Erscheinung der Blattasymmetrie brachte Wydler im Jahre 1857. Er zählte eine große Menge von Formen auf mit asymmetrischen Blättern in den verschiedenen Teilen von Laub und Blüte und suchte sie auch nach ihrer gegenseitigen Lage an der Pflanze unter zwei großen Gruppen einzuordnen; dabei unterschied er zwischen homotropen und antitropen Blättern: Beim ersten Typus liegen die großen Blatthälften in spiraliger Richtung, wie z. B. die Kronblätter von Vinca, beim zweiten Typus dagegen befinden sie sich auf derselben Seite der Sproßachse, wie z. B. bei Ulmus, Begonia und anderen; diese Gruppe umfaßt also die dorsiventralen Sprosse mit asymmetrischen Blättern. Versuche, die Erscheinung kausal $\mathrm{zu}$ erklären, wurden zuerst gemacht von Hofmeister und Wiesner 1868. Beide brachten sie in Zusammenhang mit der Lage der Blätter zum Horizont und glaubten sie als Schwerkraftwirkung deuten zu können. Nach Hofmeister sollte diejenige Blatthälfte, welche vor der Entfaltung dem Horizont abgekehrt liege, während der Dauer dieser Lage im Wachstum gefördert sein und größer werden. Wiesner dagegen faßte die spätere Lage ins Auge und unterschied hier drei Möglichkeiten:

1. Die orthotrope Lage, welche zur Bildung radiärer Formen führe;

2. Die hemiorthotrope Lage (die senkrecht zur Blattfläche durch den Mittelnerv gelegte Ebene bildet mit dem Horizont einen Winkel von $90^{\circ}$, wie z. B. bei Blättern grundständiger Rosetten), diese führe $\mathrm{zu}$ dorsiventralen Formen;

3. die klinotrope Lage, welche asymmetrische Blätter bedinge; hier bildet die durch den Mittelnerv senkrecht zur Blattfläche gelegte Ebene mit dem Horizont einen schiefen Winkel. Als besonders deutliches Beispiel führte Wiesner die geteilten Blätter an (II, 1892). Den Einfluß der Schwerkraft dehnte er auch auf die verwandte Erscheinung der Anisophyllie aus, bei welcher gleichfalls infolge der Lage zum Horizont die unteren Blätter größer würden als die oberen. Auch Frank (I) faßte diese Verhältnisse so auf und brachte, wenigstens für Koniferen, auch experimentelle Beweise. Daneben wurde auch das Licht als möglicher Reiz ins Auge gefaßt. 
Goebel dagegen betonte neben diesen äußeren Einwirkungen von Anfang an die Tatsache, daß Anisophyllie und Blattasymmetrie zumeist gebunden seien an dorsiventrale Sprosse, also in Beziehung ständen zur Gesamtsymmetrie des Sprosses, und daß die Richtung der Sproßdorsiventralität in mehreren Fällen, nämlich bei den Seitensprossen mancher Pflanzen, ausschließlich aus der Lage zur Abstammungsachse erklärt werden könne. Auch Wiesner gab diesen „inneren Ursachen“, für die er den Namen Exotrophie bzw. Endotrophie einführte, einen immer größeren Raum.

Die Experimente, welche bis jetzt angestellt wurden, beschäftigen sich fast nur mit dem Einfluß äußerer Reize, ohne hier zu einem einheitlichen Ergebnis geführt zu haben. Mit Ausnahme einer kurzen unvollendet gebliebenen Arbeit Gentner's besitzen sie alle das Gemeinsame, daß niemals versucht wurde, den Mechanismus, welcher schließlich die verschiedenen Asymmetrien ermöglicht oder herbeiführt, genauer zu zergliedern.

In den nachfolgenden Untersuchungen wurde daher besonders dies ins Auge gefaßt und auf Grund der dabei gefundenen Tatsachen versucht, einen Beitrag zur Erklärung der Erscheinung zu liefern.

Sehr viele geteilte Blätter zeigen eine Asymmetrie der Einzelblättchen in der Weise, daß deren basale Hälfte gefördert erscheint gegenüber dem der Blattspitze genäherten Teile. Rubus-, Vitis-Arten, Vicia Faba, viele Umbelliferen, überhaupt eine sehr große Zahl von Pflanzen mit geteilten Blättern zeigen diese Verhältnisse. Hofmeister nun schreibt, diejenige Seite, welche später zur größeren werde, liege im Jugendzustande oben; während dieser Lage werde die Asymmetrie ausgebildet. In der geschlossenen Knospe, zu einer Zeit, wo die einzelnen Teile der Blätter noch keine gesetzmäßige Lage zum Horizont besäßen, sei auch keine konstante Form der Asymmetrie vorhanden.

Wiesner sieht in der ganzen Erscheinung der Blattasymmetrie offenbar mehr eine phylogenetisch erlangte Beziehung zur Lage, ohne daß diese noch kausal für die Formentwicklung nötig sei; wenigstens lassen sich einige Sätze nicht anders verstehen. Nur dürfen wir in einem Falle, wo die Schwerkraftwirkung zur Ausbildung einer Erscheinung nicht notwendig ist, in ihr auch nicht die Ursache derselben annehmen. Übrigens besteht auch die Beziehung zwischen hemiorthotroper Lage mit symmetrischer Blattgestalt einerseits und klinotroper Lage mit asymmetrischer Blattform andererseits nicht regelmäßig; ab- 
gesehen davon, daß viele Pflanzen völlig symmetrische Fiederblättchen besitzen trotz klinotroper Lage, wie z. B. Fraxinus, Sambucus, Rosa u. a., finden sich auch häufig asymmetrische Endfiederchen bei hemiorthotroper Lage; fast an allen oben angeführten Pflanzen läßt sich dies gelegentlich beobachten.

Auch schließt der Verlauf der Entwicklung eine Wirkung der Schwerkraft aus; offenbar beruhen, wie dies auch Goebel schon hervorgehoben hat (II, pag. 106), Hofmeister's Angaben auf unrichtigen Beobachtungen. Mit Ausnahme von Tamarindus indica wird die Asymmetrie bei den Pflanzen, die ich untersuchte, wie Rubus fruticosus, Aegopodium podagraria, Chelidonium maius, Vicia Faba, gleich mit der Ausbildung einer Spreite angelegt. Die jungen Gewebehöcker, aus denen die Seitenfiederchen hervorgehen, legen sich sehr früh in die Richtung der Sproßachse, so daß die Mittellinien von Endblättchen und Seitenblättchen parallel laufen (Fig. 1). Erst in dieser Lage wird eine Spreite ausgebildet; die Blättchen falten sich ein, ebenso wie das ganze Blatt. Man kann hier also nicht von einer oberen bzw. unteren Hälfte der Seitenfiedern sprechen, sondern nur von einer Innenbzw. Außenseite und zwar ist die geförderte Seite die außen liegende. Erst später legen sich die Seitenblättchen in die am fertigen

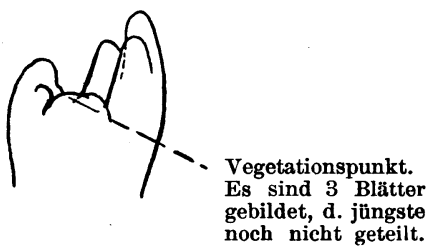

Fig. 1. Rubus. Blatte vorhandene Richtung, so daß ihre Mittellinien mit der des Endblättchens einen größeren Winkel bilden. Bei paarig geteilten Blättern, wie Vicia Faba, wird die Stelle des Endblättchens von der anfangs verhältnismäßig viel kräftigeren Rhachis eingenommen. Ich ließ nun Pflanzen von Vicia Faba in vertikaler Richtung, aber genau umgekehrt sich entwickeln, ohne jedoch die geringste Änderung der Blattform zu erreichen.

Als anderer von außen wirkender Reiz wurde das Licht aufgefaßt. Doch erhielt ich hier dieselben negativen Resultate; weder Aegopodium noch Vicia oder Pisum sativum zeigten eine Veränderung ihrer Asymmetrie, wenn sie von ihrer Keimung an im Dunkeln gehalten wurden. Nun wäre es wohl denkbar, daß vielleicht der Reihenfolge der Entwicklung ein bestimmender Einfluß zukäme, etwa in dem Sinne, daß bei basipetaler Entwicklung die unteren Hälften ihr starkes Breitenwachstum erhielten infolge der längeren Wachstumsdauer an der Blattbasis. Doch scheint eine solche Gesetzmäßigkeit nicht zu bestehen. Basipetale Entwicklung findet sich z. B. bei Vitis, Chelidonium; bei 
vielen Umbelliferen dagegen wie auch Aegopodium werden die Blättchen in akropetaler Reihenfolge angelegt; trotzdem besitzen sie die gleichen Symmetrieverhältnisse mit geförderter Basalhälfte. Ebenso finden wir auch bei Pflanzen mit symmetrischen Fiederblättchen beide Möglichkeiten der Entwicklung: Rosa z. B. zeigt basipetale, Juglans, Fraxinus, viele Papilionazeen dagegen besitzen akropetale Entwicklungsfolge.

Wir müssen somit nach anderen Zusammenhängen suchen. Es. fällt bei der Anlage der Blättchen auf, daß die äußeren (später unteren) Hälften sich auf einem breiteren Areal erheben als die innen (später oben) liegenden. Falls nicht später im Blatte selbst eine beliebige Verteilung der Stoffzufuhr stattfindet, liegt die Annahme nahe, daß diejenige Blatthälfte zur größeren wird, welcher in den ersten Entwicklungsstadien das größere Areal zur Verfügung steht, wahrscheinlich weil hier von unten her auch die Stoffzufuhr größer sein wird; eine Eigentätigkeit der Blattadern kommt auf diesem Stadium noch nicht in Frage, überhaupt müssen wir in dieser nur den späteren deutlicheren Ausdruck sehen für die Zonen stärkster Streckung gleich nach der Anlage (siehe Deinega 1898).

Es fragt sich also, ob derartige Differenzen in der quantitativen Verteilung der Stoffzufuhr bei der Anlage des Blattes eine Asymmetrie hervorrufen können, welche auch später, nach Ausbildung der Anastomosen, noch erhalten bleibt.

Versuche in dieser Hinsicht sind bereits gemacht worden von Gentner (Flora 1909); er schnitt junge Blätter an der Basis einseitig ein und erhielt dadurch asymmetrische Formen, die eingeschnittene Hälfte blieb im Wachstum dauernd zurück. Ich wiederholte seine Versuche mit demselben Resultate. Dabei ist es gleichgültig, ob man den Blattstiel durchschneidet oder im Blatt selbst eine der großen Adern; stets bleibt der Teil, dessen geradlinig von unten kommende Leitungsbahnen durchschnitten werden, bedeutend zurück. Ein Ausgleich kommt auch später nicht zustande. Fig. 2-5 zeigen Blätter von Ribes nigrum. Der Blattstiel besitzt ungefähr dreieckige Gestalt; die auf der Unterseite verlaufenden Leitbündel versorgen die Blattmitte, die seitlich nach oben zu liegenden Leitbündel die basalen Seitenteile. Durchschneidet man den Blattstiel einseitig, so erhält man ein asymmetrisches Blatt; führt man den Einschnitt auf der Unterseite des Blattstiels aus, so entsteht eine Form mit gestautem Mittelteil; wird der obere Teil des. Stiels durchschnitten, so erhält das Blatt langgestreckte Gestalt mit schwach entwickelten Basalflügeln. Gefiederte Blätter reagieren in der Weise, daß bei einseitigem Einschnitt die Blättchen auf dieser Seite 
in ihrer Länge bedeutend zurückbleiben. Man kann eben durch zeitweilige Verminderung der Stoffzufuhr im Jugendzustand jede beliebige Blattform hervorrufen; die Versorgung durch seitliche Anastomosen genügt hier offenbar nicht. Anders scheint dies am ausgewachsenen Blatt zu sein; ich behandelte solche, gleichfalls an Ribes nigrum, ganz in derselben Weise, ohne daß jedoch irgend eine Reaktion auftrat. Die verletzten Blätter hielten sich in voller Gesundheit, ohne zu welken, bis in den Herbst, wie die normalen. Auch bei Ulmus, wo die Anastomosen zwischen den großen fiedrig stehenden Adern sehr schwach zu sein scheinen, führte die Durchschneidung des Mittelnerven kein Welken

infolge von ungenü- Fig. 2. Normales Blatt. gender Wasserzufuhr herbei. Diese Beobachtung steht im Widerspruch mit Angaben K üs t e r's, welcher angibt, an Blättern mit fiedriger Nervatur ein Absterben derselben nach derartigen Versuchen beobachtet $\mathrm{zu}$ haben (I, pag. 144).
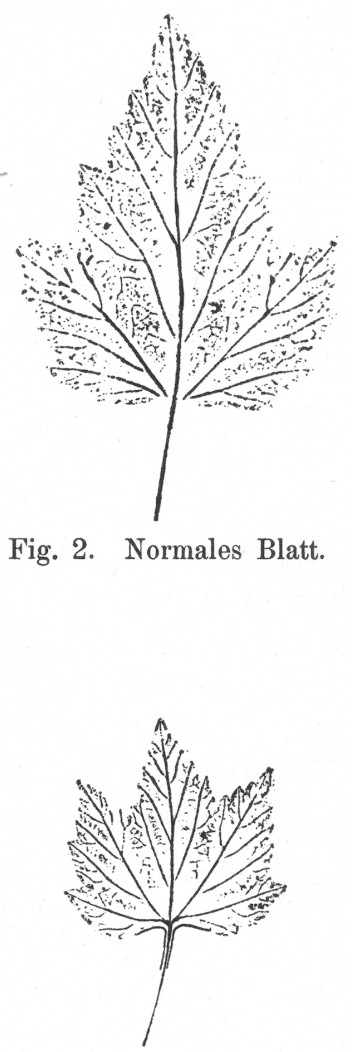

Fig. 4. Blattstiel unterseits eingeschnitten.

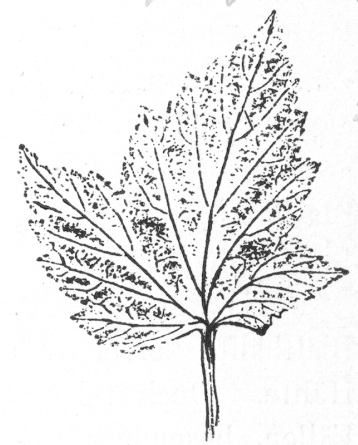

Fig. 3. Blattstiel rechts seitlich eingeschnitten.

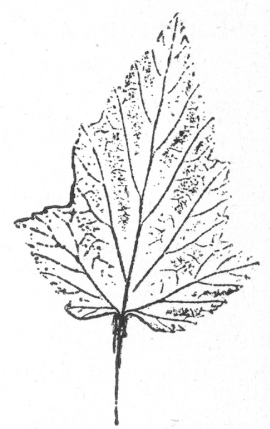

Fig. 5. Blattsiel oberseits eingeschnitten.

Ebenso wie durch

Verletzung des Blattstiels läßt sich die Form des Blattes verändern auch dadurch, daß man die Sproßachse kurz unterhalb des Vegetationspunktes einseitig einschneidet; Monokotyle und Dikotyle reagieren in gleicher Weise.

Tradescantia zebrina z. B. besitzt zweizeilig stehende asymmetrische Blätter; das Flächenverhältnis der beiden Blatthälften ist ungefähr 4:5. 
Ich schnitt die Sproßachse ein, kurz unterhalb des Vegetationspunktes auf der Seite der größeren Blatthälften; dabei machte ich stets viele Einschnitte nebeneinander, da sonst der Gefäßbündelanschluß im Stamme zu schnell verläuft und die Geschwindigkeit dieser Regeneration natürlich nicht größer sein darf, als die des Blattwachstums, wenn der Einfluß der Stoffzufuhr untersucht werden soll. In den Knoten, wo ringförmige Anastomosen sich befinden, scheint der Ausgleich doch langsam vor sich $\mathrm{zu}$ gehen. Ich erhielt eine deutliche Verminderung der Asymmetrie, meist wurden die beiden nächsten Blätter betroffen, welche ungefähr symmetrische Gestalt besaßen. Durch denselben Eingriff gelang es an Viburnum, asymmetrische Blattform $\mathrm{zu}$ erzielen. Einen starken Ausschlag erhielt ich bei Klugia zeylanica. Diese Gesneracee besitzt sehr stark asymmetrische Blätter in zweizeiliger Anordnung; durch Einschnitte in die Sproßachse auf der Seite der großen Blatthälften gelang es, deren Asymmetrie von dem Verhältnis 1:3 oder 1:2,5 der Flächen auf $1: 1,2$ oder $1: 1,5$ herabzumindern.

Es wäre denkbar, daß die Hemmung oder Entfernung der einen Blatthälfte korrelativ einen fördernden Einfluß ausübe auf die gesunde Hälfte. Doch scheint dies nicht der Fall zu sein. In den meisten Fällen, besonders bei den Versuchen an Tradescantia, blieb das ganze Blatt etwas kleiner als normal; in anderen Fällen schien doch auch die unverletzte Hälfte nicht größer geworden zu sein. Sogar die gänzliche Entfernung einer Blatthälfte, wie ich dies bei Klugia ausführte, zeigte keine Ergebnisse in dieser Hinsicht. Dagegen war hier der Mittelnerv auf der verletzten Seite in der Ausbildung der Gefäße und im Längenwachstumbedeutend zurückgeblieben, so daß die stehengebliebenen Blatthälften sich stark sichelförmig krümmten.

Auch eine nachträgliche Vergrößerung des bereits angelegten Blattes bzw. eines Blatteiles ist möglich. Ich versuchte dies zu erreichen, indem ich an noch sehr jungen Blättern der einen Hälfte ein größeres Areal der Sproßachse zuteilte als der anderen. Coleus arabicus besitzt isophylle Blattpaare mit symmetrischen Blättern bei gegenständiger Blattstellung; Unregelmäßigkeiten in der Gestalt kommen fast nie vor. Ich entfernte nun, sobald es die Größe ermöglichte, immer ein Blatt an jedem Blattpaare, und zwar ließ ich zwei benachbarte Blattzeilen stehen. Da die Sproßachse im unteren normalen Teile radiär ist, wird offenbar in die Hälften, welche auf der Seite der entfernten Blätter stehen, eine größere Stoffmenge fließen, da hier auch mehr Areal (auf dem Querschnitt) zur Verfügung steht. Die Versuche bestätigten diese Annahme vollkommen; in allen Fällen, wo die Blätter 
nicht durch die Operation verletzt waren, wurden sie asymmetrisch, die größere Hälfte lag nach der Seite hin gewendet, auf welcher die Blattzeile des gekreuzt stehenden Paares weggeschnitten war; die Breiten der betreffenden Blatthälften betrugen 19 und $22 \mathrm{~mm}, 7$ und $9 \mathrm{~mm}$, 9 und $11 \mathrm{~mm}$. Fig. 6 zeigt diese Verhältnisse, $a I$ und $b I$ sind die entfernten Blätter. Setzt man das Experiment am selben Sproß längere Zeit hindurch fort, so bleibt diese Reaktion bei den zuletzt gebildeten Blättern aus, da durch die Entfernung der Blattzeilen die Gefäßbündel dieser Sproßseite völlig reduziert werden. Läßt man, noch bevor diese Leitbündelreduktion eingetreten ist, beide Blätter eines Paares stehen, so wird dieses anisophyll, und zwar befindet sich das größere Blatt, wie anzunehmen, auf der operierten Sproßseite; offenbar hat diese Vergrößerung ihren Grund darin, daß hier die von unten aufströmende Nahrung nicht vorher schon zum Teil zur Versorgung von darunterstehenden Blättern verwendet wird, wie dies normalerweise der Fall ist. Der Grad der so erreichten Anisophyllie betrug $19: 25 \mathrm{~mm}, 17: 19 \mathrm{~mm}, 21: 28 \mathrm{~mm}$ in der Länge der beiden Blätter je eines Wirtels.

Wir sehen also, wie sehr das Wachstum eines Blattes abhängig ist von der Verteilung der Stoffzufuhr; wird diese einseitig geschwächt, so bedeutet dies eine Hemmung des betreffenden Blatteiles, wird sie verstärkt, so bewirkt ihr Zuströmen eine Vergrößerung der betreffenden Blattpartien. Während im allge-

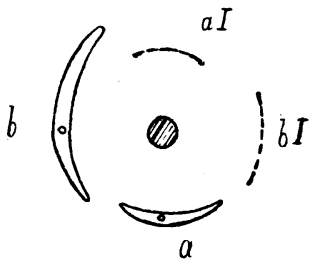

Fig. 6. Coleus arabicus. Diagramm. $a I$ und $b I$ sind die entfernten Blätter. meinen besonders die geradlinig von unten kommende Nahrung von Bedeutung ist, wird die Asymmetrie bei den Versuchen an Coleus offenbar durch die seitlich einströmende Nahrung herbeigeführt. Dieser letzte Vorgang hatte in einigen Fällen zur Bildung abweichend geformter Blätter geführt. Es befanden sich solche an dem ersten Blattpaar, das ich unverletzt hatte stehen lassen, und zwar war das Blatt auf der operierten Sproßseite unregelmäßig gewachsen; es war nicht nur größer, als das gegenüberstehende Blatt, sondern auch seine Mittellinie war seitlich verschoben nach der Seite hin, auf welcher die Blattzeile des gekreuzt stehenden Paares entfernt waren; der junge Gewebehöcker war hier stark verbreitert worden, so daß ein breites Blatt mit zwei gabelig stehenden großen Nerven entstanden war; in einem anderen Falle trat die gleiche Bildung mit derselben Stellung auf. Auch in der Natur treten derartige abweichende Formen auf, die zum großen Teil wohl durch Verwachsen von zwei sehr 
nahe aneinander gerückten Anlagen entstehen, wie dies Klein beschrieben hat.

Ganz anders als das Blatt verhält sich der Vegetationspunkt; seine radiäre oder dorsiventrale Natur ist vollkommen unabhängig von der Verteilung der Nahrungszufuhr. Auch wenn bei den Versuchen an Coleus die Leitungsbahnen der verletzten Seite gänzlich reduziert waren und so die Ernährung eine streng einseitige sein mußte, war die Symmetrie des Vegetationspunktes doch nicht verändert worden, die Blattpaare waren bei ihrer Anlage stets isophyll. Ebenso verhielt sich Klugia. Ich entfernte hier mehrere Monate hindurch sorgfältig gleich nach der Anlage der Blätter die großen Blatthälften; trotzdem besaßen die neugebildeten Blätter stets die alte Symmetrieform, der Vegetationspunkt war durch die einseitige Ernährung nicht beeinflußt worden.

Kehren wir nun nach diesen allgemeineren Untersuchungen über das Blattwachstum wieder zurück zur Erklärung der Symmetrieverhältnisse, wie sie sich in der Natur finden.

Betrachten wir eine Pflanze von Rubus oder Aegopodium z. B. bezüglich ihrer Blätter, so zeigt es sich, daß sehr häufig auch ungeteilte, nur eingeschnittene oder eingebuchtete Blätter auftreten, besonders an der Basis eines Sprosses. Die Nervatur ist hier nun ganz dieselbe wie bei geteilten Blättern. Die zwischen zwei großen Nerven liegenden Teile sind verhältnismäßig klein gegenüber den breiten basalen Randpartien. Diesen Typus von Nervatur finden wir sehr oft bei Blättern mit breiter Basis und fingerförmiger Nervatur: Acer, Ribes, Vitis u. a. gehören gleichfalls hierher. Offenbar ist die Form der Nervatur ein konstanteres und wesentlicheres Merkmal als der Umstand, ob das einzelne Blatt nun eingebuchtet oder ganz geteilt ist.

Die ziemlich häufig vorkommende unregelmäßige Asymmetrie des Endfiederchens bei akropetaler Entwicklung läßt sich leicht verstehen. In allen Fällen befindet sich die kleinere Hälfte des Endblättchens auf der Seite, auf welcher das der Spitze am nächsten stehende zuletzt gebildete Seitenblättchen inseriert ist; sind die beiden letzten Seitenfiederchen in gleicher Höhe inseriert, so ist das Endblättchen symmetrisch; rücken aber diese beiden etwas auseinander, so wird das Endblättchen asymmetrisch und es bleibt diejenige Seite kleiner, auf welcher das Seitenblättchen nach der Spitze hin verschoben ist (Fig. 7 u. 8). Soviel ich sehen konnte findet sich diese Erscheinung nur bei Blättern mit akropetaler Entwicklung, wie Juglans, Fraxinus; die Abgliederung eines 
Seitenblättchens kurz vor der Streckung bedeutet für den Gewebehöcker, der zum Endblättchen wird, eine einseitige Schwächung, welche dann zur Asymmetrie führt.

Einen besonderen Fall stellt Tamarindus indica dar. Wir treffen hier in den jüngsten Entwicklungsstadien die normale Form an mit Förderung der basalen Hälften; allmählich jedoch verschiebt sich das Verhältnis und am ausgewachsenen Blatte hat sich schließlich auf der apikalen Hälfte ein ziemlich starker Flügel entwickelt, während die basale Hälfte zurückgeblieben ist. Diese Verschiebung geht völlig unabhängig von äußeren Einflüssen vor sich; die Blätter werden in akropetaler Reihenfolge angelegt und bei völlig gleicher Lage der einzelnen Blättchen besitzen am selben Blatte häufig die untersten Fiedern bereits die Endform, die oberen dagegen noch eine geförderte Basalhälfte

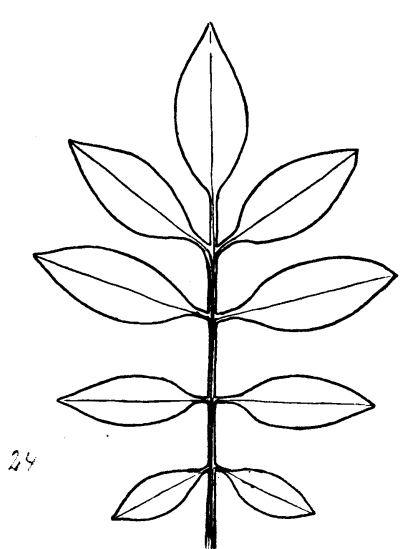

Fig. 7.

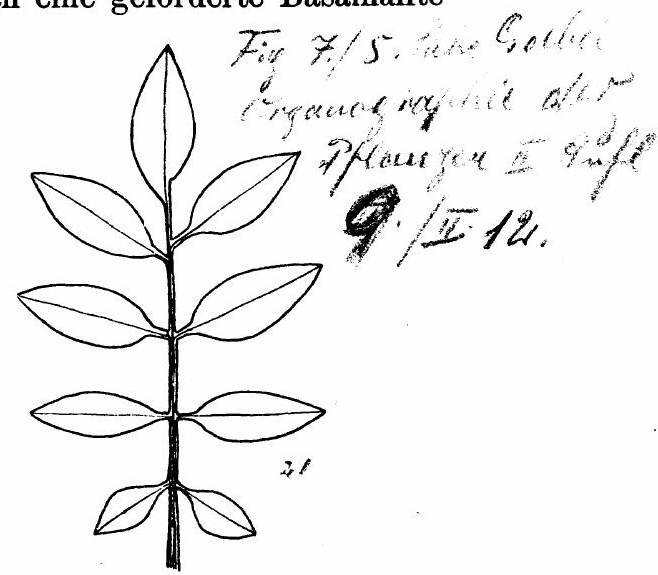

Fig. 8.

oder symmetrische Gestalt. Dagegen findet diese Veränderung gleichzeitig statt mit der Ausbildung des Blattgelenkes; an der Basis eines jeden Fiederblättchens befindet sich ein ziemlich starkes, als Gelenk funktionierendes Gewebepolster, welches ziemlich spät erst zur Ausbildung gelangt. Dieses Polster nun befindet sich auf der ursprünglich größeren Seite und es ist vielleicht möglich, daß seine Ausbildung hemmend einwirkt auf den Nahrungszufluß nach dieser Hälfte, da es die hierher gehenden großen Nerven bedeckt. Durch die einseitige Lage des Gewebepolsters unterscheidet sich Tamarindus auch von Robinia; hier sind die Fiedern symmetrisch, das Gelenk liegt in der Mitte.

Die gleichen Verhältnisse wie bei Phanerogamen treffen wir bei den geteilten Blättern der Farne an. Von äußeren Faktoren muß hier 
die Schwerkraft ganz in Wegfall kommen, da infolge der Rollung der jungen Wedel keine konstante Lage beibehalten wird. Dagegen schien nach einer Angabe von Maheu (pag. 24) dem Licht eine gewisse Bedeutung zuzukommen. Pflanzen von Aspidium spinolosum, welche in Höhlen bei einseitig eindringendem Lichte wuchsen, besaßen Fiederblättchen, deren basale Hälfte größer war als die apikale; an normalen Blättern sei dies umgekehrt. Ich untersuchte nun alle im Münchener botanischen Garten befindlichen Stöcke und fand stets denselben Fall, daß auch bei normalen Blättern die basale Hälfte gefördert war; auch bei lange andauernder Kultur in einseitig einfallendem Lichte ließ sich keine Verstärkung der Asymmetrie erzielen. Ebensowenig konnte ich an Pflanzen von Asplenium viride, welche ich lange im Dunkeln hielt, abweichende Symmetrieverhältnisse beobachten; hier ist stets die der Spitze zugekehrte Hälfte stärker entwickelt, eine Form, die wir bei Farnen häufig antreffen, z. B. Aspidium lonchitis, Nephrolepis acuta u. a.

Wie bei Phanerogamen, treten auch bei Farnen häufig asymmetrische Endblättchen auf, deren Vorkommen demselben Gesetze folgt wie bei jenen; auch läßt ja die Entwicklung auf ähnliche Verhältnisse schließen. Einschnitte zeigen dasselbe Resultat, nur werden Teile, welche man in der Jugend durch Durchschneiden des Nerven, der sie ernährt, abtrennt vom übrigen Blatte, später überhaupt nicht mehr weiter entwickelt; allmählich vergilben sie und sterben ab. Auch erwachsene Blättchen, deren Hauptnerv man an der Basis durchschneidet, vergilben, aber erst nach mehreren Monaten, so daß die Ursache auch hier nicht in Mangel der Wasserzufuhr gesucht werden darf. Einschnitte am Hauptnerv eines Wedels bewirken eine dauernde Hemmung der Fiedern oberhalb der Einschnittstelle. Diese Versuche wurden ausgeführt an Nephrolepis acuta, einem Farne mit dichotomer Nervatur. An Polypodium pustulatum dagegen, dessen Nervatur reichliche Anastomosen besitzt, war nach Durchschneiden eines großen Nerven keinerlei Welken zu beobachten.

Hier anreihen möchte ich die asymmetrischen Nebenblätter. Am auffallendsten sind sie bei Rosa und vielen Papilionaceen entwickelt. Die Asymmetrie ist von Anfang an gegeben, doch nimmt sie meistens im Weiterwachstum etwas zu; die kleinere Hälfte liegt stets innen, dem Laubblatte zugekehrt. Einen interessanten Fall bieten die Verhältnisse bei Lathyrus aphaca; nach der Bildung von zwei Primärblättern werden zwei Blätter entwickelt mit asymmetrischen Nebenblättern. Primärblätter und die beiden ersten Blätter gleichen ganz denen von Pisum. Von nun an aber werden nur mehr die Nebenblätter ausgebildet, die 
eigentlichen Laubblätter bleiben rudimentär, an ihrer Stelle treten Ranken auf; die Nebenblätter sind dann größer als die zuerst gebildeten und ganz oder fast ganz symmetrisch. Das Laubblatt wirkt hier hemmend auf die Entwicklung des Nebenblattes überhaupt, besonders aber auf dessen inneren Hälfte. Die Nahrung, welche bei der Ausbildung des Laubblattes in dessen junge Anlage gelangt, tritt nun, wenn dieses rudimentär wirkt, in die Innenhälften der Nebenblätter ein, diese stark vergrößernd. Sehr häufig findet man nun Nebenblätter, welche weder völlige Symmetrie zeigen, noch auch die starke Asymmetrie der untersten Nebenblätter; hier findet man stets eine starke Achselknospe vor, welche schon in sehr jungem Stadium angelegt wird und anscheinend die gleiche hemmende Wirkung ausübt, wie die Anwesenheit des Laubblattes. Experimentell ließ sich eine Änderung der Nebenblätter durch frühzeitiges Entfernen der Laubblätter weder bei Vicia noch Pisum herbeiführen, was bei dem raschen Wachstum der Nebenblätter ja auch kaum zu erwarten ist.

Wenden wir uns nun den Fällen $z u$, in denen das ganze Laubblatt asymmetrische Gestalt besitzt. Nach den einleitenden Untersuchungen werden wir von vornherein erwarten, daß sie besonders auftreten an dorsiventralen Sprossen mit ungleichseitig ausgebildeter Achse.

Eine deutliche Beziehung zur Außenwelt treffen wir bei den dorsiventralen Moosen und Lycopodiaceen an.

Für einige Leber- und Laubmoose ist bekannt, daß ihre Dorsiventralität durch das Licht bedingt ist. Ein sehr stark dorsiventrales Laubmoos ist auch Cyathophorum bulbosum: Auf der Oberseite stehen zwei Zeilen großer asymmetrischer Blätter mit schiefer Insertion, auf der Unterseite eine Zeile kleiner symmetrischer quer inserierter Blätter; das Moos wächst plagiotrop. Die Keimpflanzen sind nach Goebel radiär und isophyll, erst später wird der Sproß dorsiventral (Goebel III, pag. 83); von nun an werden schon am Scheitel die Blätter ungleich groß angelegt, auch sind die Oberblätter von Anfang an asymmetrisch, die großen Hälften einander zugekehrt; wir sehen deutlich, wie von oben nach unten die Kraft allmählich abnimmt. Läßt man Pflanzen bei abgeschwächtem Lichte wachsen, so stirbt der Hauptsproß ab; es treiben Seitensknospen aus, welche $\mathrm{zu}$ sehr kleinen, anscheinend ganz radiären Stämmchen werden. Eine genauere Untersuchung zeigt aber, $\mathrm{da} B$ die Dorsiventralität hier nur sehr stark abgeschwächt ist, aber nicht aufgehoben: die Insertion von zwei Blattzeilen ist schief, während eine 
Reihe quer inseriert ist. Eine ähnliche Wirkung kann erreicht werden durch sehr trockene Kultur; die klein bleibenden Pflänzchen wachsen wie auch bei abgeschwächtem Licht meist völlig orthotrop und sind bis fast zur Spitze dicht mit Rhizoiden bedeckt. Während normalerweise die Länge der Oberblätter $7-8 \mathrm{~mm}$, die der Unterblätter $3-3,5 \mathrm{~mm}$ beträgt, sind bei Trockenkultur die entsprechenden Zahlen 1,3-1,5 mm bzw. 1-1,3 mm. Wasserkulturen zeigen gleichfalls eine Verminderung der Dorsiventralität; die Oberblätter waren hier durchschnittlich $2 \mathrm{~mm}$ lang, die Unterblätter 1,2 mm. Da hier nur die Blätter klein blieben, das Stämmchen dagegen ein fast gar nicht vermindertes Längenwachstum zeigte, boten die Pflanzen ein sehr schlankes langgestrecktes Bild. Ganz allgemein scheinen demnach ungünstige Bedingungen eine Hemmung der Dorsiventralität zu bedeuten. Trotzdem kommt doch dem Lichte anscheinend eine spezifische Wirkung zu. Legt man erwachsene Pflanzen umgekehrt auf Torf, die kleinen Blätter nach oben gerichtet, so drehen sich die Stämmchen um $180^{\circ}$ und erreichen so ihre natürliche Lage. Schwache Exemplare dagegen drehen sich nur so weit, bis wieder zwei Blattzeilen nach oben zu liegen kommen, zuerst also eine Zeile mit großen und eine Zeile mit kleinen Blättern; nun aber tritt eine Verschiebung ein: das Segment, welches anfänglich nur kleine Blätter gebildet hat, bildet nun große Blätter mit schiefer Insertion, das unten liegende dagegen bildet statt wie früher große nun kleine Blätter mit querer Insertion.

Bei den Lycopodien und Selaginellen sehen wir gleichfalls die Anisophyllie und Asymmetrie der Blattausbildung zusammengehen mit der dorsiventralen Natur der Sproßachse. Radiäre Formen besitzen symmetrische gleichgroße Blätter, dorsiventrale dagegen zeigen eine im gleichen Sinne verlaufende Anisophyllie.

Bei dorsiventralen Selaginellen finden wir auf der Oberseite zwei Reihen kleiner, auf der Unterseite zwei Reihen großer Blätter; alle Blätter sind asymmetrisch, die großen Blatthälften liegen nach unten, gleichlaufend mit der Anisophyllie; das Stämmchen ist bekanntlich im gleichen Sinne dorsiventral, die Unterseite besitzt mehr parenchymatisches Gewebe. Die Anisophyllie tritt bereits in den jüngsten Stadien deutlich hervor, die Asymmetrie der Unterblätter dagegen erst später; zunächst liegen die Blätter in der Richtung der Sproßachse, den Vegetationspunkt schützend; doch behält die Unterhälfte ihre Teilungsfähigkeit länger bei und mit der Entwicklung des starken Flügels an der Basis der Unterblätter wird auch die spätere Lage herbeigeführt, durch welche die Spreite nach außen geschoben wird. Daß man nicht an 
eine Reaktion der einzelnen Blätter auf Licht oder Schwerkraft denken kann, zeigen die in den Gabelachseln stehenden Blätter; meist sind die beiden Gabeläste ziemlich ungleichwertig, der eine wächst, sich weitergabelnd, kräftig fort, während der andere bald zurückbleibt; die Achselblätter sind nun asymmetrisch und zwar liegt die größere Hälfte stets auf der Seite des stärkeren Gabelastes, eine Differenz, welche offenbar bedingt ist durch den Kraftunterschied der beiden Äste gleich bei der Teilung des Vegetationspunktes. Eine Abhängigkeit von äußeren Einflüssen besteht bei den meisten Selaginellen wohl kaum, dagegen werden Sprosse von Lycopodium complanatum, wie Goebel gezeigt hat, bei LichtauschluB radiär (Goebel, II, pag. 217) und für manche Selaginella-Arten ist eine ähnliche Wirkung des Lichtes wahrscheinlich.

Die Dorsiventralität äußert sich weiterhin auch in den Wurzelträgern; angelegt werden solche stets auf beiden Seiten, doch kommt meist nur der auf der Unterseite gebildete zur Entwicklung. Läßt man durch Entfernung der Sproßspitze die jüngsten Wurzelträgeranlagen als beblätterte Sproße austreiben, so besitzen die beiden jungen Stämmchen dieselbe Differenz. Merkwürdig ist, daß bei dem auf der. Oberseite austreibenden Sproß zur stärkeren Seite die oben (außen) liegende wird; erst durch nachträgliche Überneigung wird die normale Lage erreicht; es erinnert diese Erscheinung fast an die als Exotrophie bezeichneten Verhältnisse der höheren Pflanzen.

Ganz ähnliche Symmetrie wie Selaginella zeigen auch viele Phanerogamen. Es gehören hierher die oft besprochenen Fälle von Ulmus, Fagus, Tilia, die Anisophyllie von Acer, Aesculus, ferner Formen, wie Goldfussia, Centradenia u. a. Auch die Koniferen, wie Abies, würden sich hier anschließen.

1. Typus. Tilia und Ulmus: Die Blätter stehen in zwei Reihen; die auf der Sproßunterseite inserierte Blatthälfte ist größer; die Keimpflanzen besitzen symmetrische Blätter. Fagus unterscheidet sich nur dadurch, daß hier die größeren Blatthälften auf der Sproßoberseite stehen; die Keimpflanzen sind radiär mit gegenständigen symmetrischen Blättern. Die Achselsprosse der Kotyledonen besitzen bereits asymmetrische Blätter wie die späteren Zweige; die Blattinsertion liegt etwas schief, die Achselknospen sind, wie bei Ulmus und Tilia, etwas nach oben gerückt.

2. Acer, Aesculus. Auch hier tritt Anisophyllie und Asymmetrie nur an Seitensprossen auf. Seitensprosse erster Ordnung tragen auf 
der Oberseite eine Reihe kleiner, auf der Unterseite eine Reihe großer symmetrischer Blätter; die beiden seitlichen Blattzeilen stehen bezüglich ihrer Größe ungefähr in der Mitte und sind asymmetrisch, die untere Hälfte ist größer. Seitensprosse zweiter Ordnung, welche der Achsel von Unterblättern entspringen, wiederholen diesen Bau, ebenso die aus der Achsel von Oberblättern stammenden, nur daß die Richtung der Symmetrie hier umgekehrt zum Horizont verläuft, indem zur geförderten Seite gleichfalls die Außenseite, hier also Oberseite, wird. Sprosse dagegen, welche in den Achseln seitlicher Blätter gebildet werden, besitzen nur mehr anisophylle Blattpaare mit asymmetrischen Blättern: eine Zeile großer Blätter steht auf der Außen-, eine zweite auf der Unterseite des Sprosses, im gleichen Sinne verläuft die Richtung der Asymmetrie. Es verhalten sich so eine Menge Pflanzen mit gegen-

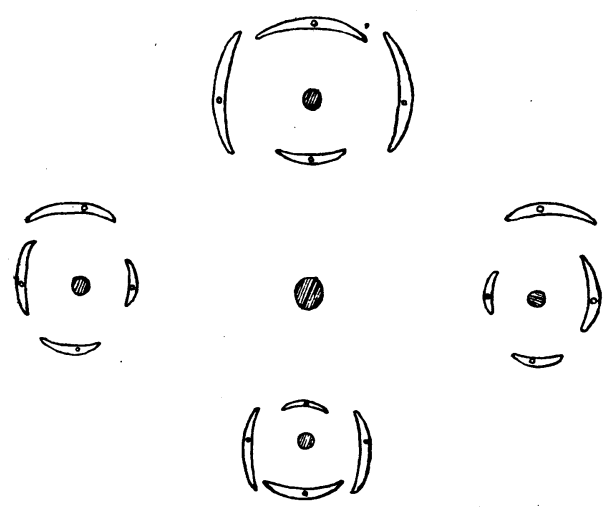

Fig. 9. Acer. Verzweigungsschema eines Seitensprosses 1. Ordnung. ständiger Blattstellung aus den verschiedensten Verwandtschaftskreisen bei nicht sehr starker Anisophyllie (Fig. 9).

3. Goldfussia. Diese Form unterscheidet sich von dem normalen Verzweigungsschema durch mehrere Abweichungen: 1. Alle Blattpaare sind sehr stark anisophyll, 2. alle Blätter sind stark asymmetrisch, die großen Blatthälften nach innen liegend, also in umgekehrter Richtung wie die Anisophyllie, 3. die Sprosse erscheinen gegen den Muttersproß schief gekreuzt, so daß oben zwei Zeilen kleiner, unten zwei Zeilen großer Blätter zu stehen kommen, 4. die unteren großen Blätter schließen einen Winkel ein von ungefähr $120^{\circ}$, sie sind auseinander gerückt.

Ohne weitere Bedeutung ist die schiefe Stellung, da sie erst nachträglich durch Drehung des zweiten Internodiums um $45^{\circ}$ erreicht wird, häufig aber auch unterbleiben kann, ohne daß damit dann noch weitere Veränderungen verknüpft wären. Die Blattasymmetrie, durch deren auffallende Richtung sich Goldfussia am stärksten unterscheidet von Acer-Seitensprossen zweiter Ordnung, wollen wir erst später genauer betrachten und jetzt nur die Anisophyllie berücksichtigen. Wie Goldfussia verhalten sich sehr viele Pflanzen mit starker Anisophyllie 
bei gegenständiger Blattstellung: Cendradenia-Arten, Columnea-Arten, Procris, Elatostema z. B. gehören hierher. Auch hier kann bei manchen, wie z. B. Centradenia rosea, die Internodiendrehung unterbleiben.

In allen Fällen ist auch, wie zu erwarten, die Sproßachse dorsiventral gebaut und ebenso der Blattstiel asymmetrisch; es verläuft eine ununterbrochene Linie einseitig gesteigerter Stoffzufuhr vom Stamm durch den Stiel in die größeren Blätter bzw. Blatthälften. Ohne eine solche Differenz könnte ja auch die Asymmetrie der Blätter nicht erhalten werden. Angelegt wird sie überall mit großer Übereinstimmung gleich mit der ersten Entwicklung. Für Fagus und Ulmus war dies schon früher nachgewiesen; für Goldfussia gilt dasselbe: Blätter mit erst $1 \mathrm{~mm}$ Spreitenlänge sind schon asymmetrisch, die Blattpaare von Anfang an anisophyll; so betrugen die Längen von Spreite und Stiel bei einigen Paaren $0,8: 2 \mathrm{~mm}$ die der Spreite 1,8:3 mm; die Blätter sind noch genau gegenständig angeordnet. Auch die Dorsiventralität der Sproßachse gibt sich von Anfang an zu erkennen. Mikrotomschnitte durch ganz junge Anlagen von Achselknospen zeigen in einem Stadium, wo diese noch nicht als selbständige Gewebehöcker sich abgetrennt haben, auf der Außenseite des sie bildenden meristematischen Gewebes bereits mehr Zellteilungen als auf der Innenseite. Als Ausnahme wurde bisher Acer bezeichnet; doch fand ich in der Knospe auch hier stets schon die spätere Symmetrieform angelegt. Anisophyllie findet man allerdings deutlich nur in den Seitenknospen der im letzten Jahre gebildeten Blätter, da sie an älteren Sprossen allmählich schwindet und ja auch in erwachsenem Zustande nur in abgeschwächtem Grade auftritt.

Als bestimmende Ursache für diese Erscheinungen wurde nun zuerst die Schwerkraft angenommen. In welcher Weise der Vorgang verlaufen sollte, war im einzelnen nie angegeben worden; offenbar aber war gedacht worden, daß nicht auf den Vegetationspunkt, sondern auf die bereits gebildeten Blätter oder den bereits angelegten Sproß die Schwerkraft als Reiz wirke und die symmetrischen Anlagen zur asymmetrischen bzw. anisophyllen Endform führe. Nach Hofmeister sollte die obenliegende Hälfte der Blätter eine Förderung erfahren, während Wiesner und die späteren, mehr die Anisophyllie betrachtend, eine Kräftigung der Unterseite infolge der horizontalen oder geneigten Lage annahmen.

$\mathrm{Da} \beta$ bei Ulmus die Lage in der Knospe (und die Asymmetrie wird ja gleich anfangs angelegt) für beide Blatthälften dieselbe ist, hat schon Sachs gezeigt; erst durch nachträgliche Drehung kommt die ursprüngliche Innenseite nach oben zu liegen (Lehrbuch der Botanik, 
2. Aufl.). Es bliebe nur, durch Erweiterung der Theorie, die Annahme übrig, daß die horizontale Lage den Muttersproß induziere, nur dorsiventrale Seitensprosse zu bilden. Doch trifft auch dies nicht zu. Ich kehrte im Juni Ulmuszweige durch eine Drehung von $180^{\circ}$ um und hielt sie in dieser Lage festgebunden bis zum nächsten Sommer. Die alten Achselknospen hatten ausgetrieben, die neuen Sprosse richteten sich senkrecht auf und legten wieder neue Seitenknospen an. Obwohl nun weder diese selbst noch ihre Muttersprosse jemals die normale Lage besessen hatten, waren sie doch dorsiventral wie gewöhnlich, mit geförderter Außenseite; die Dorsiventralität kommt hier völlig unabhängig von einer Schwerkraftwirkung zustande. Ebenso verhält sich Goldfussia; auch hier stehen die Achselknospen in den verschiedensten Richtungen, völlig senkrecht bis horizontal, die auf der Oberseite eines geneigten Sprosses gebildeten sogar völlig umgekehrt; trotzdem sind sie schon in den jüngsten Stadien exotroph entwickelt, auch gelingt es nicht, durch Änderung der Lage die Symmetrie zu beeinflussen. Ohne jeden Zwang wachsen häufig anisophylle Sprosse in senkrechter Richtung und unter gewissen später zu besprechenden Bedingungen gelingt es, radiäre Sprosse zu ziehen auch bei sehr starker Neigung.

Die meisten Versuche waren bisher an Acer und Aesculus ausgeführt worden. Frank gibt an, durch einfache Drehung um $180^{\circ}$ an Seitensprossen erster Ordnung von Acer platanoides auch die Richtung der Anisophyllie völlig umgekehrt zu haben in einem Zeitraum von 14 Tagen, also an Blättern, welche alle in normaler Lage angelegt waren (I, pag. 873); es scheint fast unmöglich, in so kurzer Zeit die Größenverhältnisse bereits angelegter Blätter derart zu verändern, und ich glaube, wir haben hier wohl eher eine Drehung anzunehmen. Goebel versuchte dasselbe an Aesculus, doch zeigte die Lage keinerlei Einfluß (I, pag. 840). Ebensowenig gelang es Weiße, durch horizontale Lage einen Hauptsproß anisophyll zu machen; auch wurden Seitensprosse, welche von Anfang an vertikal wuchsen, trotz dieser Lage nicht isophyll. Er wies übrigens zum ersten Male darauf hin, daß bei längerem Wachstum stets der Grad der Anisophyllie allmählich abnimmt auch bei horizontaler Lage. Nordhausen nun scheint es in einigen Fällen gelungen zu sein, einen Ausschlag bei Veränderung der Lage zu erhalten, in anderen wieder erhielt er negative Ergebnisse. Er gibt an, durch Drehung eines Sprosses im Dunkeln eine nachträgliche Änderung erlangt zu haben, in dem Sinne, daß die Schwerkraft die Ausbildung der Unterseite fördere. Auch isophylle Hauptsprosse wurden durch Entwicklung in geneigter Lage anisophyll. Leider sind nirgends Zahlen angeführt. 
Figdor gibt für Versuche an Acer platanoides dasselbe Resultat an; die Länge der Blattspreiten betrug $5,7: 7,5 \mathrm{~cm}$ und $6,2: 7,5 \mathrm{~cm}^{1}$ ) (II, pag. 288). Für Aesculus führt er Versuche an, in welchen bei Dunkelkultur an Seitensprossen erster Ordnung durch Drehung um $90^{\circ}$ die lateralen Blattpaare anisophyll wurden; die Zahlen sind für die Länge der Blattspreiten 3,5:4,1 cm und 2:2,5 cm (III, pag. 131). Ferner gelang es an Hauptsprossen von Aesculus durch geneigte Lage, unter $45^{\circ}$, im Verlauf von 5 Jahren Anisophyllie hervorzurufen: Von acht Sprossen waren sechs schwach anisophyll geworden; die Zahlen der im Herbst gemessenen Blattspreiten sind 20,5:25 cm, $21: 22,4 \mathrm{~cm}$ (III, pag. 133 ff.) ${ }^{1}$ ). Alle Versuche, in welchen bei senkrechtem Wachstum eine Verminderung der Anisophyllie erzielt wird, sind kein stichhaltiger Beweis, da dies normalerweise auch bei horizontaler Lage der Fall ist. Außerdem liegt noch eine Angabe von Kolderup Rosenvinge vor, nach welcher es möglich sein soll, an Centradenia floribunda durch Umkehrung die Anisophyllie zu verändern. Ich wiederholte seinen Versuch, konnte jedoch kein eindeutiges Resultat erhalten, da die Sprosse sich meistens drehen und außerdem bei längerem Wachstum gleichfalls isophyll werden.

Jedenfalls geht aus diesen Versuchen hervor, daß der Wirkung der Schwerkraft doch nur eine untergeordnete Rolle zukommt. Dies zeigen auch die median inserierten Blattpaare von Seitensprossen zweiter Ordnung, welche trotz gleicher Lage der Blätter zum Horizont anisophyll sind, ferner die auf der Oberseite entspringenden Achselsprosse, deren obere Hälfte die geförderte ist, ebenso die Tatsache, daß der Grad der Anisophyllie auch bei horizontaler Lage allmählich schwindet. Es sind auch andere Pflanzen bekannt, welche genau dieselbe Erscheinung aufweisen, und wir werden sehen, daß man deren Symmetrieform ändern kann und daß sie völlig unabhängig von äußeren Einflüssen zustande kommt. Auch Regenerationserscheinungen, wie siè Küster beschrieben hat, reihen sich hier an. An Hypokotylen von Anagallis wurden Sprosse regeneriert, deren erstes Blattpaar median stand und anisophyll war mit geförderter Außenseite; diese Beziehung war bei jeder Lage gewahrt geblieben (K ü ster, II).

Als weitere Ursache wurde das Licht angesehen, wohl infolge der teleologischen Deutung der ganzen Erscheinung. Bei Formen wie Acer,

1) An den zitierten Stellen sind diese Zahlen als Millimeter angegeben; auf eine Anfrage hatte Herr Prof. Dr. Figd or die Liebenswürdigkeit, mir mitzuteilen, daß durch ein Versehen Millimeter anstatt Zentimeter als Maß angegeben sei, und ersuchte mich, dies hier zu berichtigen. 
Goldfussia und ähnlichen wird durch ihre eigentümliche Symmetrie die Assimilationsfläche immer weiter nach außen gerückt und zugleich eine allzu dichte Beschattung im Inneren der Krone vermieden; ebenso wird wohl auch bei Begonia Rex z. B. oder anderen kriechenden Pflanzen die Dorsiventralität von Bedeutung sein; bei Tilia, Fagus und Ulmus jedoch scheint es sehr fraglich, ob ein derartiger Vorteil geboten wird.

Die Versuche dagegen, welche bis jetzt angestellt sind, geben ein ziemlich unklares Bild. Betrachten wir die strahlenförmige Symmetrie von Goldfussia, so werden wir an einen richtenden Einfluß des Lichtes wohl kaum denken, sondern ihn eher auffassen als Reiz überhaupt, welcher die Exotrophie hervorrufen würde; der Reiz müßte also stattfinden auf den Muttersproß oder gleich bei der ersten Anlage der Achselknospe. Die allein genaue Versuchsanstellung ist also wohl die, daß wir von einem völlig im Dunkeln wachsenden Sprosse neue Knospen im Dunkeln anlegen lassen. Ich führte dies an Goldfussia aus, indem ich an geköpften Sprossen alle bereits angelegten Seitenknospen entfernte und sie dann bei gänzlichem Lichtabschluß weiter wachsen ließ; einige bildeten nun neue Knospen aus, welche auch austrieben und mehrere Blattpaare entwickelten. Anisophyllie und Asymmetrie der Blätter war aber keineswegs vermindert, sondern eher in verstärktem Grade aufgetreten, in einigen Fällen bis zur fast völligen Reduktion der Oberblätter. An Acer obtusatum haben ähnliche Versuche Frank's dasselbe Resultat geliefert, ebenso fand dies Goebel bei Aesculus und Centradenia; auch Nordhausen und Figdor erhielten Anisophyllie bei Dunkelkultur an Acer platanoides und Aesculus hippocastanum.

Alle übrigen Versuche nun fußen auf der Vorstellung, daß die Anisophyllie durch ungleich starke Beleuchtung der beiden Sproßseiten zustande komme. Nun ist es natürlich jederzeit möglich, durch Regulierung des Lichtzutrittes eine Abstufung in große und kleine Blätter $\mathrm{zu}$ erreichen; die schwächer beleuchteten werden eben in ihrem Wachstum zurückbleiben. Nordhausen hat an Acer und Aesculus derartige Versuche mit einseitig zutretendem Lichte gemacht, ebenso Figdor (Figdor, I). Dieser ließ ferner Centradenia- und Goldfussia-Sprosse bei einseitiger Beleuchtung wachsen und zwar traf das Licht zuerst die Seite mit den kleinen Blättern, eine Stellung, welche eigentlich der natürlichen genau entspricht. Er erhielt nun eine starke Verkleinerung der sonst großen Unterblätter, während die Oberblätter an Größe zunahmen; nach seiner Beschreibung war die Lichtintensität auf beiden Seiten des Sprosses sehr stark verschieden (Figdor, III, pag. 142). 
Ich glaube, diese dem Vorkommen in der Natur und meinen eigenen Versuchen so widersprechenden Ergebnisse sind wohl einfach durch Etiolement zu erklären; daß die Oberblätter größer wurden, kann auf korrelativer Wirkung beruhen. Entfernt man an Goldfussia z. B. die großen Unterblätter, so erreichen die Oberblätter bedeutend größere Dimensionen als normal.

Nur für Fagus und Ulmus scheint Nordhausen die Lichtwirkung nicht im Sinne eines einseitigen Etiolements aufgefaßt zu haben. Er nahm an, daß bei Fagus das Licht hemmend, bei Ulmus fördernd auf die Asymmetrie überhaupt einwirke. Experimentelle Ergebnisse erhielt er jedoch nicht, und auch meine verdunkelten Sprosse gingen leider zugrunde. Doch genügen auch Beobachtungen in der Natur. Stets zeigt sich bei Fagus, daß die ersten drei Blätter eines Sprosses stark asymmetrisch sind, das vierte weniger stark; die nächsten Blätter sind dann ganz oder fast ganz symmetrisch; ebenso wird auch die anfangs schiefe Insertion allmählich quer. Eine direkte Wirkung des Lichtes scheint demnach ausgeschlossen, da ja die Blätter desselben Sprosses an der Basis asymmetrische, an der Spitze symmetrische Gestalt besitzen, obwohl sie gleicher Beleuchtung ausgesetzt sind. Man könnte höchstens denken, daß das Licht die Bildung längerer Sprosse begünstigt; tatsächlich findet man im Inneren der Krone mehr kurze Sprosse mit drei oder höchstens vier Blättern als am Rande der Krone. Doch besitzen auch Bäume, welche dicht im Walde stehen und wenig Licht erhalten, am Rande gleichfalls Zweige mit einer größeren Zahl von Blättern, welche dann symmetrisch sind, genau wie bei Bäumen, welche der Sonne ausgesetzt am Waldrand stehen. Auch bei Ulmus findet ein solcher Übergang zu symmetrischer Blattbildung statt. Stets ist nicht nur das Endblättchen, wie früher angenommen, symmetrisch. Äußere Einflüsse spielen sonach offenbar kaum eine Rolle bei der in Frage stehenden Erscheinung.

Die Dorsiventralität der Sprosse kommt nun nicht nur in den Blättern und der Stammanatomie zum Ausdruck, sondern auch in anderen Eigenschaften, worauf auch $\mathrm{W}$ i e s n e r beständig hingewiesen hat (II, 1892; VI, 1895). Die geförderte Sproßseite wächst stärker in die Dicke und bei vielen Formen auch in die Breite, wie z. B. bei Goldfussia, wo infolgedessen die Blätter auf der Unterseite etwas auseimandergerückt werden; dasselbe findet sich bei Klugia und mehreren Begonia-Arten. Auch die Seitenknospen werden in ungleicher Größe angelegt; bei Aesculus z. B. befinden sich auf der Unterseite große, fast stets austreibende Achselknospen, während die der Ober- 
seite häufig fast ganz verkümmern. Dasselbe gilt auch für Goldfussia; bei Centradenia rosea trägt jedes Unterblatt einen Achselsproß, während die Oberseite gar keine Knospen anlegt. An Stecklingen werden die ersten Wurzeln stets auf der stärkeren Seite gebildet, und da dies auch an Pflanzen mit geförderter Ober-(Innen-)Seite der Fall ist, wie z. B. bei Begonia hirsuta und Begonia Duchartrei, können wir diese Tatsache auch nicht als eine Nachwirkung der Schwerkraft erklären. Bei Procris werden in den Achseln der großen Blätter weibliche, in denen der kleinen Blätter männliche Blütenstände gebildet. — Die Blütensprosse von Tilia sind Achselsprosse diesjähriger Blätter; das Flugblatt stellt das Vorblatt der Oberseite dar, das der Unterseite ist zwar kleiner, trägt aber stets eine kräftige Achselknospe, welche im nächsten Jahre austreibt.

Ich möchte hier noch kurz die Erscheinung besprechen, welche man speziell mit Epitrophie und Hypotrophie des Holzes bezeichnet hat. Bei den meisten unserer Laubhölzer ist der Holzkörper auf der Oberseite stärker ausgebildet als auf der Unterseite. Doch ist nur Fagus bis in die Spitze epitroph, bei allen übrigen tritt die Epitrophie erst später auf; die Spitze ist, wie wir dies oben gesehen haben, auf der Unter-(Außen-)Seite stärker entwickelt. Aesculus war z. B. $21 \mathrm{~cm}$ hinter der Sproßspitze epitroph im Verhältnis 1,8:2 mm infolge des kambialen Wachstums, während die jüngsten Teile eine deutliche Förderung der Unterseite zeigten. Zwischen Dorsiventralität des Sprosses und der späteren Kambiumtätigkeit scheint keinerlei Zusammenhang zu bestehen. Letztere ist anscheinend abhängig von der Lage zum Horizont, von atmosphärischen Einflüssen und Druckverhältnissen (siehe Kny, II, und die Arbeiten Ursprung's).

Anisophyllie und Blattasymmetrie sind demnach nur ein Spezialfall der Exotrophie. Wir haben an den Coleus-Versuchen gesehen, daB Verschiedenheiten in der Stoffzufuhr zur dauernden Ausbildung der Anisophyllie nötig sind und sie sogar direkt hervorrufen können. Letzteres ist hier nicht der Fall, da sie schon vor der Ausbildung des Stammgewebes auftritt, dessen Asymmetrie nur die bereits angelegte Form erhält. Als Ursache müssen wir somit die dorsiventrale Natur des Vegetationspunktes bezeichnen, die sich in der Bildung eines ungleichseitigen Sprosses ausdrückt.

Es ist nun wichtig, daß fast an allen in Frage stehenden Pflanzen gelegentlich auch radiäre Sprosse auftreten mit symmetrischen Blättern bzw. isophyllen Blattpaaren. Die Pflanzen von Goldfussia glomerata Nees im Münchener botanischen Garten z. B. besitzen fast stets einige 
solche Triebe; es fällt an diesen auf, daß sie weniger reich verzweigt sind als die anisophyllen Triebe. Achselknospen sind wohl überall angelegt, treiben aber nicht aus; meist sind auch die Internodien länger und ziemlich viele Blattpaare gebildet, die Sprosse machen einen kräftigen Eindruck. Um diese Form eventuell künstlich hervorzurufen, schnitt ich nun an Stecklingen und auch an Zweigen an der Planze selbst jedesmal sorgfältig die noch ganz jungen Achselknospen heraus; es wurden auf dem Blattstiel immer wieder neue regeneriert und auch diese stets entfernt. Nach einiger Zeit nun erhielt ich völlig isophylle Sprosse mit symmetrischen Blättern (Fig. 10). Die mit der Kultur als Steckling verbundene mehr senkrechte Lage kommt nicht in Betracht; solche

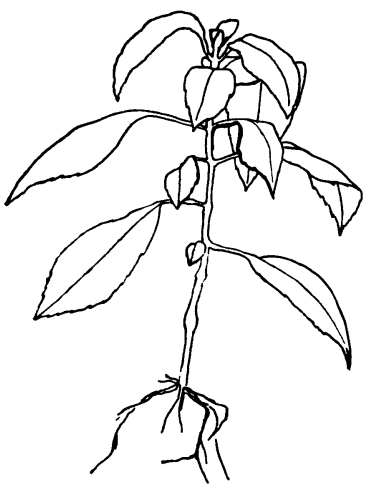

$a$

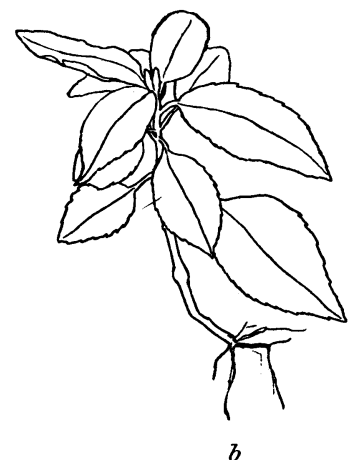

$b$

Fig. 10. Radiär gewordene Goldfussia-Sprosse (infolge des beschriebenen Verfahrens); die beiden Abbildungen sind nach Photographien durchgepaust und gezeichnet, um in der Reproduktion die Verhältnisse deutlicher hervortreten zu lassen.

Stecklinge, deren Achselknospen ich nicht entfernte, wuchsen anisophyll weiter wie zuvor. Ich möchte einige Zahlen folgen lassen, welche stets die Spreitenlängen von aufeinanderfolgenden Blattpaaren desselben Sprosses darstellen.

1. Steckling: 1. $3,6: 7,5 \mathrm{~cm}$

2. $7,0: 9,5$,

3. $9,5: 9,7$,

4. $7,4: 7,4$,

5. $4,6: 4,4$,

2. Steckling: 1. $6,0: 6,0 \mathrm{~cm}$

2. $10,6: 10,6$,

3. $4,0: 4,0 \quad \%$ (verkümmert)

4. $9,0: 9,0$ " 
1. Sproß am Stamm: 1. $7,0: 8,5 \mathrm{~cm}$

2. $7,5: 7,5 \quad$,

3. $9,5: 11,0$,

2. Sproß vom Stamm: 1. 4,7:6,5 cm

2. $5,7: 6,3 \quad$,

3. $4,0: 4,5$,

An derselben Pflanze waren die normalen Größen z. B.:

1. $3,0: 9,0 \mathrm{~cm}$

2. $5,0: 10,0$,

3. $4,0: 12,0$,

4. $3,5: 9,0$,

Stamm und Verzweigung sind an diesen Trieben gleichfalls nach allen Seiten hin gleichmäßig entwickelt. Irgend eine Beziehung zur Lage besteht nicht; es gelang, radiäre Sprosse $\mathrm{zu}$ erhalten auch bei sehr starker Neigung. So lag ein Sproß in seinem unteren Teil völlig horizontal, in seinem oberen $40^{\circ}$ geneigt, andere besaßen eine Neigung von $30^{\circ}, 60^{\circ}$ usw. und wurden trotzdem isophyll. 'Untersuchen wir die Seitensprosse dieser Triebe weiter, so zeigt es sich, daß an ihnen nur die median inserierten Blattpaare anisophyll sind; bei den lateralen findet sich gar keine oder nur schwache Anisophyllie. Wir haben also hier dieselben Verhältnisse wie an Acer-Seitensprossen erster Ordnung; auch erhält man durch Weiterverzweigung wieder die gewöhnliche Goldfussia-Symmetrie, die ja gleichfalls der von Acer-Sprossen zweiter Ordnung entspricht. Man hat nun hier für die lateral stehenden anisophyllen Blattpaare stets eine Schwerkraftwirkung angenommen; doch glaube ich, daß hier noch die dorsiventrale Natur des Muttersprosses zum Ausdruck kommt, der seiner Achselknospe die eigene Exotrophie aufdrückt. Wir müssen eben bedenken, daß die Seitensprosse zweiter Ordnung nicht von gleichseitig ausgebildeten selbständigen Organen gebildet werden, sondern von solchen mit starker Abhängigkeit.

Ähnliche Resultate hat bereits Nordhausen an Ulmus erhalten, doch faßte er nur die Gestalt der Blätter ins Auge, ohne an die Dorsiventralität des Sprosses zu denken. Er erhielt dadurch, daß er vor dem Austreiben alle Achselknospen bis auf eine einzige entfernte, am austreibenden Sprosse nach der Spitze hin ganz symmetrische Blätter. Ich wiederholte diesen Versuch mit dem gleichen Ergebnis; die schon angelegten Blätter bleiben asymmetrisch, die neugebildeten sind symmetrisch. Diese Sprosse sind bedeutend länger und bilden mehr Blätter als die anderen Zweige. 
Es fragt sich nun, welcher Art der Reiz ist, durch den der Muttersproß auf den Seitensproß einwirkt und dessen Dorsiventralität hervorruft.

Bei gewissen Koniferen, wie Abies z. B., ist diese gebunden an eine dauernde Einwirkung des Hauptvegetationspunktes; wird dieser entfernt oder in seiner Funktion geschwächt, so richten sich zunächst mehrere Seitentriebe auf, bis einer wieder die anderen in ihrer Lage und Form zurückhält. Die Richtung der Dorsiventralität ist hier nach mehreren Untersuchungen durch äußere Reize $\mathrm{zu}$ beeinflussen, wie Frank und Kny gezeigt haben (Frank, I, 1868; II, 1873; Kny, I, pag. 433; siehe auch Goebel, Vergl. Entwicklungsgeschichte, pag. 146).

Anders scheinen die Verhältnisse bei Laubpflanzen zu liegen. Eine dauernde Einwirkung des Hauptvegetationspunktes auf die Seitensprosse scheint nicht zu bestehen, da diese auch bei voller Kraft des Muttersprosses radiär werden. An Adventivknospen findet sich Dorsiventralität sehr häufig selbst dann, wenn bei ihrer Anlage der Vegetationspunkt des Muttersprosses nicht mehr am Leben ist. Es gelten diese Tatsachen für Goldfussia glomerata. Auch völlig getrennt von der Pflanze kommen dorsiventrale Formen zustande: Blattstecklinge regenerieren neue Triebe, welche teils radiär, teils dorsiventral sind, ebenso gilt dies von Internodienstecklingen.

Fragen wir uns nun, in welcher Weise das Entfernen der Achselknospen auf den Vegetationspunkt wirkt, so denken wir wohl an eine verstärkte Nahrungszufuhr Dabei ist es aber nicht etwa eine gleichmäßigere Verteilung derselben - eine solche wäre ja auch nicht imstande die Symmetrie des Vegetationspunktes zu ändern - sondern offenbar nur die Gesamtkräftigung, welcher diese Wirkung zukommt. Im unteren Teile bleibt die Sproßachse noch stark dorsiventral, dann ändert sie sich fast plötzlich und wird radiär mit isophyllen Blattpaaren. Der Übergang des Vegetationspunktes von dorsiventraler $\mathrm{zu}$ radiärer Natur ist ein ganz unvermittelter. $\mathrm{Da}$ bei den Blättern der Übergang nicht so schnell vor sich geht, hat seinen Grund darin, daß auch die isophyll angelegten Blattpaare infolge der ungleichseitigen Stammanatomie und der damit verbundenen ungleichen Ernährung verschiedene Ausbildung ihrer Blätter erfahren.

Auch andere Eigentümlichkeiten scheinen dafür zu sprechen, daß die Dorsiventralität durch einen Schwächungsreiz auf den Vegetationspunkt des Seitensprosses zustande kommt. An Goldfussia-Stecklingen gelingt es nicht immer, in gleicher Zeit radiäre Form zu erzielen bei 
Entfernen der Achselknospen; die länger anisophyll bleibenden Sprosse sind aber deutlich schwächer, sie wachsen langsamer, ihr Grün ist weniger frisch, die Internodien bleiben kürzer. An Blattstecklingen läßt sich die merkwürdige Tatsache beobachten, daß symmetrische, von isophyllen Trieben stammende Blätter sich durchgehends eher bewurzeln als asymmetrische; selbst wenn alle Blätter von derselben Pflanze genommen wurden und so nicht an einen verschiedenen Gesundheitszustand derselben gedacht werden konnte, war dies der Fall; ebensowenig spielte die Größe der Blätter eine Rolle. Auch die früher erwähnte Beobachtung, daß im Dunkeln gewachsene Goldfussia-Sprosse verstärkte Anisophyllie zeigten, läßt sich auf Schwächung zurückführen. - Figdor hat bei Goldfussia glomerata und Goldfussia anisophylla gleichfalls isophylle Sprosse beschrieben und hervorgehoben, daß sie stets sehr kräftiges Wachstum besaßen.

Auch normalerweise findet bei kräftigen Seitensprossen überall ein Übergang zur radiären Form statt. Wachsen Seitenzweige von Acer und Aesculus längere Zeit kräftig fort, so verlieren sie ihre Anisophyllie, wie Fagus seine Asymmetrie; letzteres gilt auch für Ulmus. $\mathrm{Da} \beta$ ŭppige Wurzelschößlinge der Ulme im oberen Teile symmetrische Blätter tragen, ist bekannt; ebenso läßt sich dies an der Linde beobachten. Bei Solanum tuberosum erstreckt sich die Dorsiventralität nur auf die unteren Teile der Seitensprosse, deren Achse hier außerordentlich stark exotroph ist; auch die Vorblätter sind in hohem Grade asymmetrisch mit geförderter Außenhälfte. An Vicia Faba-Seitensprossen ist das erste Fiederblatt asymmetrisch; hier ist das Innenblättchen größer, es liegt also Endotrophie vor wie bei Fagus und mehreren Begonia-Arten.

Die sogenannte herbstliche Anisophyllie dagegen läßt sich gut verstehen als Schwächung infolge der ungünstigeren Vegetationsbedingungen, durch welche dann die ursprüngliche Dorsiventralität wieder hervorgerufen wird.

Einen gewissen Wert kann man vielleicht auch dem Vergleich verschiedener Pflanzen beimessen. Es scheint, je schwächer und kürzer die Seitenzweige sind, desto stärkere Asymmetrie aufzutreten. Wir finden verhältnismäßig schwache Dorsiventralität bei Centradenia floribunda; hier ist jeder Vegetationspunkt imstande, eine große Anzahl von Blättern $\mathrm{zu}$ bilden und auch die Internodien erreichen beträchtliche Längen. Bei Centradenia rosea dagegen ist der Grad der Dorsiventralität sehr stark; jeder Seitensproß bildet hier nur zwei oder drei Blattpaare 
mit fast völlig unterdrückten Indernodien. Auch durch Entfernen aller übrigen Knospen läßt sich der. Vegetationspunkt solcher Sprosse nicht zu längerem Wachstum veranlassen. Ein sehr hoher Grad von Dorsiventralität, gleichfalls durch Exotrophie zustande kommend, liegt bei mehreren von Wiesner beschriebenen Gardenia-Arten vor; die Blätter stehen dekussiert, am medianen Blattpaar verkümmert das innere Blatt völlig; an jedem Seitensproß werden überhaupt nur zwei Paare entwickelt, zwischen welchen jede Internodienbildung unterbleibt, so daß zuletzt drei Blätter in einem Quirl zu stehen scheinen (Wiesner, IV). An Viscum album hat Heinricher gleichfalls Anisophyllie infolge von exotrophem Wachstum beobachtet und zwar an Pflanzen, welche sehr reiche Verzweigung besaßen (Heinricher 1910).

Ähnliche Verhältnisse finden sich übrigens auch bei Moosen. Goebel gibt für Climacium dendroides und Mnium undulatum an, daß dorsiventrale Seitensprosse, wenn sie mit dem Boden in Berührung kommen und Rhizoiden gebildet haben, zu radiärem Wachstum übergehen (Goebel, II, pag. 354).

Ein klarer Nachweis dafür, daß die Dorsiventralität einer Gesamtschwächung ihre Entstehung verdankt, wäre freilich erst erbracht, wenn es gelänge, radiäre Sprosse durch schlechte Bedingungen wieder zur ursprünglichen Form zurückzuführen; doch habe ich bis jetzt noch kein solches Resultat erhalten, es ist wohl auch die Dauer des Versuches noch zu kurz.

In anderen Fällen besitzen allerdings schon die Keimpflanzen dorsiventrale Natur, wie z. B. bei Klugia und Elatostema. Merkwürdig verhielten sich sechs Keimpflanzen von Columnea sanguinea: zwei derselben besaßen die Form von Seitensprossen zweiter Ordnung bei dekussierter Blattstellung, alle Blattpaare waren anisophyll; bei vier Pflanzen jedoch war nur die Hälfte der Blattpaare anisophyll, die anderen besaßen zwei gleich- oder fast gleichgroße Blätter, ihre Symmetrie glich der von Seitensprossen erster Ordnung. Erst im Laufe der weiteren Entwicklung traten auch hier nur mehr anisophylle Blattpaare auf. Überall war deren Grad noch schwächer als an alten ausgewachsenen Pflanzen.

Ich möchte hier einen weiteren Fall anreihen. Es handelt sich nicht um einen Seitenzweig, sondern um einen Hauptsproß. An Vicia Faba werden zuerst zwei kleinbleibende Primärblätter gebildet, dann zwei oder drei völlig symmetrische Blätter mit je einer Fieder auf 
jeder Seite, dann mehrere Fiederblätter, welche zum Teil symmetrisch sind, zum Teil aber auf der einen Seite zwei, auf der anderen Seite nur ein Fiederblättchen besitzen. An Viciakulturen, welche ich lange Zeit hatte trocken stehen lassen, machte ich nun die Beobachtung, daß gelegentlich Blätter auftraten, welche deutlich asymmetrisch waren, indem die beiden Fiederblättchen beträchtliche Größenunterschiede aufwiesen. Ich versuchte dies nun künstlich hervorzurufen dadurch, daß ich manche Kulturen von Anfang an sehr trocken hielt oder vor der Aussaat drei Viertel der Kotyledonen wegschnitt. In allen Fällen besaß ein ziemlich hoher Prozentsatz der Pflanzen nun asymmetrische Blätter, deren Stellung auf eine Dorsiventralitằt des Sprosses hinwies; die größeren Fiederblättchen standen alle auf derselben Seite; auch an den Nebenblättern trat diese Differenz auf, sie waren größer auf der Seite der größeren Fiederchen. Ebenso war die Sproßachse dorsiventral geworden, sowohl in der Entwicklung der Gefäße als auch des Parenchyms. Der Größenunterschied der Fiederchen desselben Blattes betrug z. B. 1,7:2,5 cm, an einem anderen Sprosse 1,4:1,6 cm, 1,8:2,0 cm, 1,9:2,1 cm (infolge der schlechten Ernährung erhielten die Blätter keine größeren Längen). Daß äußere Kräfte hier nicht im Spiele sind, zeigt die völlig orthotrope Wachstumsrichtung der dorsiventral werdenden Sprosse, ferner für Licht der Umstand, daß auch Pflanzen, welche von Anfang an im Dunkeln keimten und lange Zeit bei Lichtausschluß wuchsen, in manchen Fällen asymmetrische Blätter bildeten. Anscheinend kommt diese latente Dorsiventralität ganz allgemein durch ungünstige Ernährungsbedingungen wieder zum Vorschein. Weniger leicht gelingt dieser Versuch bei Pisum sativum; meist werden hier nur die Nebenblätter auf beiden Sproßseiten verschieden groß entwickelt.

Wenden wir uns nun zu einem anderen Typus von Blattasymmetrie. Schon oben haben wir erwähnt, daß bei Goldfussia die Richtung der Blattasymmetrie derjenigen der Dorsiventralität und Anisophyllie gerade entgegengesetzt verläuft: die großen Blatthälften stehen immer nach der Innenseite des Sprosses hin zugekehrt. Verfolgen wir diese Asymmetrie durch den Blattstiel zurück in den Stamm, so zeigt sich, daß auch der Stiel asymmetrisch ist, und von der Verteilung der Stoffzufuhr gibt die Anatomie der Sproßachse ein deutliches Bild. Es erhalten auf dem Querschnitt (wenn wir zwei Blattpaare in eine Ebene projizieren) die Oberblätter weniger, die Unterblätter mehr als einen Quadranten; Fig. 11 zeigt dies. Die Blätter werden in genau gegenständiger 
Anordnung angelegt. Teilen wir nun den Stamm durch eine vertikale und eine horizontale Linie ( $a$ und $b$ ) in vier Quadranten, welche normaler Weise das Areal der einzelnen Blätter darstellen würden, und vergleichen wir damit die tatsächlichen Verhältnisse von Goldfussia, so tritt der Unterschied klar hervor: die Unterblätter erhalten noch Nahrung aus den nächstoberen Quadranten, ihre Oberhälfte vergrößernd, während den Oberblättern dieser Teil gleichsam entrissen wird. Da die Mittellinie der Blätter nicht in gleichem Maße nach oben verschoben wird, muß die untere Hälfte der Innenblätter kleiner werden, als die obere. Offenbar handelt es sich hier um eine Korrelationserscheinung; es wird bei der Anlage den Unterblättern ein größeres Areal zugeteilt, wodurch gleichzeitig die Oberblätter geschwächt werden müssen.

Deutlich treten diese Beziehungen hervor bei einem Vergleich mit Acer. Asymmetrie und Anisophyllie verlaufen hier in gleicher Richtung, ihr Grad entspricht ungefähr dem der anatomisch sichtbaren Sproßdorsiventralität. Bei Goldfussia dagegen würde diese allein noch keine ausreichende Erklärung bieten für das hohe $\mathrm{Maß}$ von Anisophyllie; im Sproß verhalten sich Innen- und Außenseite, d. i. die dem Muttersproß zu- bzw. abgewendete Seite, wie $3: 5$ oder $5: 6$, die Längen der Spreiten von Innen- und Außenblättern dagegen durchschnittlich wie 1:4. Die Förderung der Außenblätter muß bei der räumlichen Verteilung der Stoffzufuhr notwendig zur Asymmetrie führen. Entfernt man längere Zeit hindurch die großen Außenblätter, so werden die sonst klein bleibenden Innen(Ober-)Blätter bedeutend größer als normal; auch ihre Asymmetrie ist etwas vermindert. Die Spreitenlänge der Oberblätter eines so

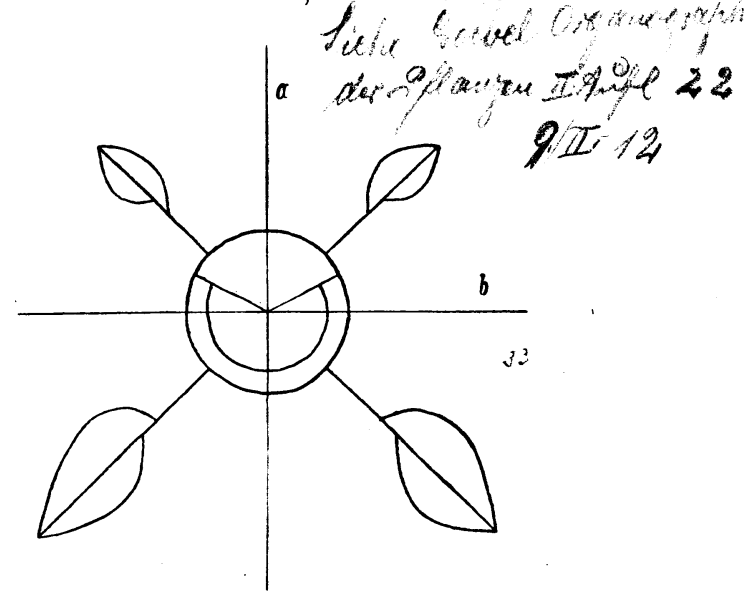

Fig. 11. Goldfussia. Diagramm. behandelten Sprosses betrug: $6 \mathrm{~cm}, 7,5 \mathrm{~cm}, 9 \mathrm{~cm}, 10,5 \mathrm{~cm}, 8,5 \mathrm{~cm}$; bei Anwesenheit der Unterblätter betrug die Blattlänge eines Paares an einem Sprosse derselben Pflanze $3: 12 \mathrm{~cm}, 3: 11,5 \mathrm{~cm}, 2: 8 \mathrm{~cm}$, 2,5:10 cm. Isophylle Sprosse besitzen nur symmetrische Blätter, schwach anisophylle ebenfalls; erst bei starker Anisophyllie werden auch die Blätter asymmetrisch. Es läßt sich dies deutlich in den verschiedenen Übergangsstadien von dorsiventraler zu radiärer Form 
beobachten. Dasselbe zeigt auch der Vergleich verschiedener Arten. Am schwächsten sind beide Erscheinungen entwickelt bei Centradenia floribunda; von da an nehmen sie zu in der Übergangsreihe: Goldfussia - Centradenia rosea, Columnea sanguinea, Centradenia grandifolia Procris laevigata, Elatostema sessile - Klugia zeylanica. Bei Elatostema werden die Oberblätter zu hautartigen Gebilden reduziert, bei Klugia überhaupt nicht mehr angelegt.

Diese zweizeilig beblätterte Form hat man schon immer abgeleitet von der bei Gesneraceen häufigeren Symmetrie der dekussierten Blattstellung durch Schwinden der zwei oberen Blattzeilen. Diese offenbar vorhandene phylogenetische Abstammung erklärt auch die Asymmetrie der Blätter. Sie sind von Anfang an asymmetrisch und entstehen am Vegetationspunkt nicht in einer Divergenz von $180^{\circ}$ (an jedem Knoten ein Blatt), sondern einander auf der Unterseite genähert; durch diese Lage erhalten die Oberhälften ein größeres Areal zugeteilt und werden bedeutend größer als die Unterhälften (Fig. 12).

Trotzdem ist die Unterseite wie bei Goldfussia die kräftigere und eigentlich produktive. Stecklinge bilden hier früher Wurzeln, es wächst diese Seite stärker in die Breite, so daß die Blätter später annähernd eine Divergenz von $180^{\circ}$ besitzen, die Blüten werden hier gebildet und eben auch die Blätter. Deutlicher noch als aus der Lage am Vegetationspunkt läßt sich dies aus folgen-

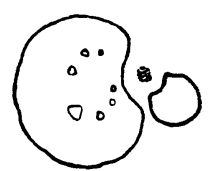

Fig. 12. Klugia zeylanica. Vegetationspunkt mit

2 Blättern.

dem Versuche erkennen: schneidet man Klugia-Sprosse auf der Seite der großen Blatthälften ein, so erhält man Blätter mit stark verminderter Asymmetrie; dagegen wächst der ganze Sproß gut weiter und die Blätter erlangen ansehnliche Längen. An einem Sproß betrugen diese bei einem derartigen Versuche oberhalb der Einschnittstelle $11 \mathrm{~cm}, 7,5 \mathrm{~cm}, 4,3 \mathrm{~cm}$, an einem anderen Sprosse $10 \mathrm{~cm}, 9,5 \mathrm{~cm}, 4 \mathrm{~cm}, 2 \mathrm{~cm}$. Einschnitte auf der Seite der kleinen Blatthälften dagegen bewirken ein völliges Zurückbleiben der Blätter und des ganzen Sprosses; die Spreitenlängen betrugen hier $5,6 \mathrm{~cm}, 5,6 \mathrm{~cm}, 3 \mathrm{~cm}$, an einem anderen Sprosse $5 \mathrm{~cm}$, $5 \mathrm{~cm}, 4 \mathrm{~cm}, 3 \mathrm{~cm}$. Der Sproß selbst wächst kaum mehr weiter. Die Versuchsdauer war in beiden Fällen die gleiche. Es zeigen diese Tatsachen deutlich, daß wir hier eine ganz anders bedingte Art von Blattasymmetrie vor uns haben als bei Tilia und Begonia z. B., bei denen ihre Richtung durch die Dorsiventralität des ganzen Sprosses bedingt wird. Gelegentlich treten bei Klugia auch auf der Oberseite Blätter 
auf, diese stehen stets an einem Knoten zusammen mit einem anderen Blatte, ungefähr in der Mitte der Oberseite und sind dann annähernd symmetrisch. An Achselsprossen entsteht das erste Blatt nach der produktiven Seite des Muttersprosses hingewendet, daß zweite Blatt auf der Außenseite (Innen- und Oberblatt verkümmern, Fig. 13). Die Symmetrieform ist dann die von Seitensprossen zweiter Ordnung an Pflanzen mit gegenständiger Blattstellung bei sehr starker Exotrophie. Doch sind hier auch schon die Keimpflanzen dorsiventral; sie wachsen völlig orthotrop und neigen sich erst später epinastisch über. - Künstlich läßt sich die Lage der Blattasymmetrie von Klugia hervorrufen

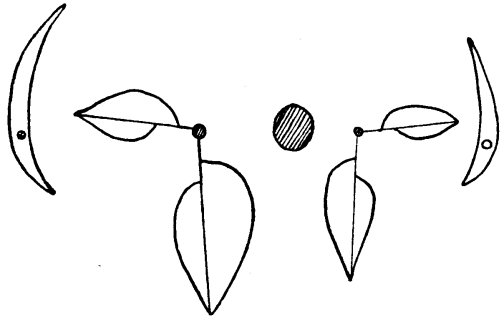

Fig. 13. Klugia zeylanica. Verzweigung. durch nachträgliche Entfernung von zwei benachbarten Blattzeilen bei dekussierter Stellung, wie dies die eingangs beschriebenen Versuche an Coleus arabicus zeigen.

Einen besonderen Fall stellen einige Xerophyten dar. Rochea falcata z. B. und etwas vermindert Rochea odorata besitzen sichelförmig gebogene Blätter, wobei die Biegung durch das stärkere Wachstum der einen Hälfte hervorgerufen wird. Die Blätter stehen dekussiert, doch etwas verschoben; die größeren Blatthälften befinden sich aber nicht auf derselben Sproßseite, sondern einander abgekehrt; beim nächsten Blattpaar wechselt die Richtung, so daß auch kein spiraliger Verlauf der Symmetrielinie vorhanden ist. Schon die Anlage der Blätter ist asymmetrisch. Fig. $14 a$ gibt ein Diagramm bei dekussierter Blattstellung, Fig. $14 b$ zeigt die Verschiebung der Mittelnerven, Fig. $14 c$ die wirkliche
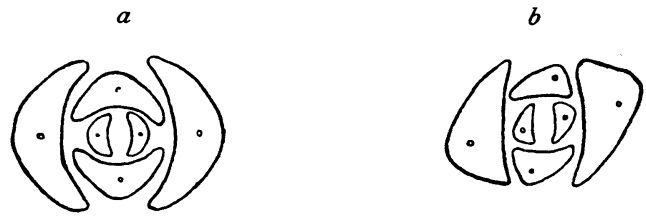

Lage. Es werden die Blätter am Vegetationspunkt mehr den Endpunkten einer Diagonale genähert angelegt, dieser streckt sich in einer Richtung und dadurch kommen alle Abweichungen zustande. Die 
Blätter werden asymmetrisch, sie rücken sich etwas näher nach zwei diagonal liegenden Reihen, die Divergenz der aufeinanderfolgenden Blattpaare ist nicht mehr genau $90^{\circ}$, es entsteht ein großer und ein kleiner Winkel. Seitensprosse besitzen diese Merkmale zunächst nur sehr schwach: fast dekussierte Blattstellung und fast symmetrische Blätter; es gilt dies für die drei ersten, kleinbleibenden Blattpaare, die Internodien sind hier noch langgestreckt. Von nun an unterbleibt deren Entwicklung, der Vegetationspunkt erhält seine schräg gestreckte Gestalt, die Blätter werden asymmetrisch und in der beschriebenen Art verschoben. Vor der Blütenbildung nimmt der Sproß wieder die erste Form an. Im Dunkeln wächst die Pflanze gut weiter, doch tritt auch hier dieselbe Umbildung des Vegetationspunktes auf. Ebenso wenig kommt natürlich die Schwerkraft in Frage.

Bei Blüten treffen wir Asymmetrie der Blätter besonders im Zusammenhang mit Zygomorphie an. Die Umbelliferen besitzen zum großen Teil in ihren dorsiventralen Randblüten sehr stark asymmetrische Kronblätter, welche sich ganz der Gesamtsymmetrie der Blüte und des Blütenstandes unterordnen, die Außenseite ist überall stärker entwickelt. Bei Papilionaceen-Blüten ist die geförderte Seite im allgemeinen sowohl in der Größe der Teile als in der Reihenfolge der Entstehung die Vorder-, innerhalb des Kronblattkreises dagegen die Hinterseite. Das mediane Blatt (Vexillum) ist hier am größten, ebenso sind die seitlichen Blätter asymmetrisch mit geförderter Oberseite. Diese Verhältnisse werden von Anfang an bestimmt. Ich ließ nun Pflanzen von Vicia Faba ankeimen und dann in genau umgekehrter Richtung weiter wachsen, indem ich sie an der Spitze durch angehängte Gewichte beschwerte und von unten her durch Spiegel beleuchtete. Es gelang einige zur Blütenbildung zu bringen, ohne daß die veränderte Lage die Symmetrieform beeinflußte. Bei Lobelia-Arten wie L. tenuior und L. erinus sind sowohl Kelch-, Kron- und Staubblätter ungleich groß. Während aber im Kelch- und Staubblattkreis die Größe der Blätter von hinten nach vorn zunimmt, verläuft bei den Kronblättern diese Linie umgekehrt. Die hinteren seitlichen Kronblätter sind auch asymmetrisch; bei Lobelia erinus liegen ihre größeren Hälften nach hinten, entsprechend der allgemeinen Zunahme der Kronblätter in dieser Richtung; bei Lobelia tenuior dagegen sind ihre größeren Hälften dem hinteren medianen Blatte abgekehrt. Bei dieser Art sind die zwei seitlichen hinteren Blätter sehr weit herauf mit dem medianen Blatte verwachsen 
und es ist möglich, daß dadurch die Ausbildung der diesem zugekehrten Blatthälfte gehemmt wird; wenigstens ist dies der einzige Unterschied der zwischen Lobelia erinus und L. tenuior deutlich hervortritt. Ebenso wie die Kronblätter sind auch die seitlichen Staubblätter asymmetrisch, die größeren Antherenhälften liegen nach vorn, entsprechend der gesamten Symmetrierichtung des Androeceums. Entwicklungsgeschichtlich tritt die Asymmetrie der Kronblätter erst später hervor, doch kommt sie bei völlig gleichbleibender Lage der Blüte zustande. Im allgemeinen scheint sich auch bei Blüten die Symmetrie der Blätter aus der der ganzen Blüte oder des Blütenstandes ableiten zu lassen, wie dies Goebel in einigen Fällen gezeigt hat (IV).

Einen speziellen Fall stellen die Blätter mit gedrehter Knospenlage dar. Diese sind stets asymmetrisch und zwar ist immer die innenliegende, stärker gerollte Seite die größere. Hier bildet sich die Asymmetrie erst allmählich aus, angelegt werden die Blätter symmetrisch. Es trifft dies für die Laubblätter von Aspidistra elatior zu und für die Kronblätter von Vinca maior, an denen ich die Entwicklung untersuchte. In einem Falle war an Vinca eine Blüte abnorm gebildet mit klappiger Knospenlage, hier waren die Kronblätter symmetrisch geblieben. Dieselben Beziehungen fand ich bei mehreren Geranium-Arten. GentianaArten wie G. Pneumonanthe und G. asclepiadea nun besitzen trotz gedrehter Knospenlage völlig symmetrische Kronblätter, welche nur in den Endzipfeln schwache Asymmetrie zeigen. Die Blätter sind jedoch an der außenliegenden Hälfte eingebogen und zurückgelegt, ihr Krümmungsgrad entspricht also ganz dem der Innenhälfte und dieser Mangel einer Differenz in der Rollung bedingt vielleicht auch ihre Symmetrie. Ob wir der stärkeren Krümmung einfach eine verstärkte Nahrungszufuhr zuschreiben dürfen oder ob Rollung und Asymmetrie nur beide gleichzeitig durch einen anderen gemeinsamen Faktor, etwa eine allgemeine spiralige Symmetrielinie, hervorgerufen werden, ist freilich fraglich.

\section{Zusammenfassung.}

1. Die Größe der einzelnen Blatteile wird bestimmt durch das Areal, das ihnen am Vegetationspunkt zugeteilt wird. Die Weiterentwicklung ist gebunden an eine entsprechende Stoffzufuhr von unten her; ebenso wie sich durch Hemmung derselben eine dauernde Verkleinerung des betreffenden Blatteiles erreichen läßt, wirkt eine ver- 
stärkte Stoffzufuhr vergrößernd ein auf das bereits angelegte Blatt. Dabei kommt hauptsächlich die von unten her geradlinig einströmende Nahrung in Betracht, die Tätigkeit der Anastomosen ist verhältnismäßig gering. Der Vegetationspunkt dagegen ist in seiner Symmetrie völlig unabhängig davon, ob die Nahrung von unten her gleichseitig oder ungleichseitig zuströmt.

2. Ein Einfluß der Schwerkraft auf das Wachstum und die Symmetrie der einzelnen Blätter konnte nicht gefunden werden.

3. Ursachen der Blattformen: Bei Fiederblättchen ist offenbar die Symmetrie der Gesamtnervatur des ganzen Blattes das bestimmende konstante Element. An dorsiventralen Organen sind Asymmetrie und Anisophyllie gleichfalls nur ein Ausdruck der Gesamtsymmetrie. Bei Formen wie Goldfussia und Klugia ist die Anisophyllie durch die Sproßdorsiventralität, die Asymmetrie der Blätter durch Korrelation zu erklären. Stets wird die Endform schon am Vegetationspunkte angelegt.

4. Die Dorsiventralität der Seitensprosse, als Exo- bzw. Endotrophie bezeichnet, kommt zustande durch eine Reizwirkung auf den Vegetationspunkt des betreffenden Sprosses, der Reiz scheint auf Schwächung zu beruhen; durch gute Ernährung läßt sich die dorsiventrale Natur des Vegetationspunktes in radiäre umwandeln. Einen Einfluß des Lichtes konnte ich nirgends finden, ebensowenig bei den untersuchten Formen einen solchen der Schwerkraft.

5. An Blüten scheint gleichfalls die Gesamtsymmetrie des Blütenstandes und der Blüte Gestalt und Richtung der Blattasymmetrie zu bestimmen.

6. Bei gedrehter Knospenlage der Blätter tritt Asymmetrie auf mit geförderter Innenhälfte.

Meinem verehrten Lehrer, Herrn Geheimrat Prof. Dr. von Goebel, erlaube ich mir für die stete Teilnahme und Unterstützung meinen ergebensten Dank auszusprechen. 


\section{Zitierte Literatur.}

Deinega, V., Beiträge zur Kenntnis der Entwicklungsgeschichte des Blattes und der Anlage der Gefäßbündel. Flora 1898.

Figd or, W., I. Über die Ursachen der Anisophyllie. Ber. d. Deutsch. bot. Ges. 1897, Bd. XV.

II. Über den Einfluß äußerer Faktoren auf die Anisophyllie. Ber. d. Deutsch. bot. Ges. 1904, Bd. XXII.

III. Die Erscheinung der Anisophyllie. Deuticke, Leipzig und Wien 1909.

Frank, I. Über die Einwirkung der Gravitation auf das Wachstum einiger Pflanzenteile. Bot. Ztg. 1868.

II. Über den Einfluß des Lichtes auf den bilateralen Bau der symmetrischen Zweige der Thuja occidentalis. Pringsheim's Jahrb. f. wissenschaftl. Bot. 1873-1874, Bd. XIX.

Gentner, G., Untersuchungen über Anisophyllie und Blattasymmetrie. Flora 1909.

Goebel, K., I. Beiträge zur Morphologie und Physiologie des Blattes. Bot. Ztg. 1880.

II. Organographie der Pflanzen. Fischer, Jena 1898-1901.

III. Archegoniaten-Studien X: Beiträge zur Kenntnis australischer und neuseeländischer Bryophyten. Flora 1906.

IV. Über Symmetrieverhältnisse in Blüten. Wiesner-Festschrift 1907.

Heinricher, E., Beiträge zur Kenntnis der Anisophyllie. Annales du Jardin Botanique de Buitenzorg 1910, 2. Serie, Suppl. III.

Hofmeister, W., Allgemeine Morphologie der Gewächse. Engelmann, Leipzig 1868.

Klein, J., Untersuchungen über Bildungsabweichungen an Blättern. Pringsheim's Jahrb. f. wissenschaftl. Bot. 1892, Bd. XXIV.

Kny, L., I. Über die Bedeutung der Florideen in morphologischer und histologischer Beziehung und den Einfluß der Schwerkraft auf Koniferenblätter. Bot. Ztg. 1873.

II. Über das Dickenwachstum des Holzkörpers der Wurzeln in seiner Beziehung zur Lotlinie. Ber. d. Deutsch. bot. Ges. 1908, Bd. XXVI.

Küster, E., I. Pathologische Pflanzenanatomie. Fischer, Jena 1903.

II. Beobachtungen über Regenerationserscheinungen. Beihefte z. bot. Zentralblatt 1903, Bd. XIV.

Maheu, J., Contributions à l'étude de la flore souterraine de France. Ann. des sciences naturelles 1906, 9 me serie, Tome III.

Nordhausen, M., Untersuchungen über Asymmetrie von Laubblättern höherer Pflanzen nebst Bemerkungen zur Anisophyllie. Pringsheim's Jahrb. f. wissenschaftl. Bot. 1902, Bd. XXXVII.

Flora, Bd. 103. 
124 K. Boshart, Beiträge zur Kenntnis der Blattasymmetrie und Exotrophie.

Rosenvinge, K., Influence des agents extérieurs sur l'organisation polaire et dorsiventrale des plantes. Revue générale de Botanique 1889.

Sachs, J., Lehrbuch der Botanik, 2. Aufl.

Ursprung, A., Untersuchungen über das exzentrische Dickenwachstum an Stämmen und Ästen. Beihefte z. bot. Zentralbl. 1906, Bd. XIX.

Weisse, A., Zur Kenntnis der Anisophyllie von Acer platanoides. Ber. d. Deutsch. bot. Ges. 1895, Bd. XIII.

Wiesner, J., I. Beobachtungen über den Einfluß der Erdschwere auf Größen und Formverhältnisse der Blätter. Sitzungsber. d. kaiserl. Akad. d. Wissensch. in Wien 1868, mathem.-naturw. Kl., Bd. LVIII, Abt. I.

II. Untersuchungen über den Einfluß der Lage auf die Gestalt der Pflanzenorgane. I. Die Anisomorphie der Pflanze. Sitzungsber. der kaiserl. Akad. d. Wissensch. in Wien 1892, mathem.-naturw. Kl., Bd. CI, Abt. I.

III. Vorläufige Mitteilung über die Erscheinung der Exotrophie. Ber. d. Deutsch. bot. Ges. 1892, Bd. X.

IV. Pflanzenphysiologische Mitteilungen aus Buitenzorg. V. Über die Anisophyllie tropischer Gewächse. Sitzungsber. d. kaiserl. Akad. d. Wissensch. in Wien 1894, mathem.-naturw. Kl., Bd. CIII, Abt. I.

V. Beobachtungen über die Anisophyllie einiger tropischer Gewächse. Ber. d. Deutsch. bot. Ges. 1894, Bd. XII.

VI. Über Trophien nebst Bemerkungen über Anisophyllie. Ber. d. Deutsch. bot. Ges. 1895, Bd. XIII.

Wydler, Über asymmetrische Blätter und ihre Beziehung zur Symmetrie der Pflanze. Flora 1857. 